Article

\title{
The Economics of Wind Power in China and Policy Implications
}

\section{Zifa Liu ${ }^{1}$, Wenhua Zhang ${ }^{2, \dagger}$, Changhong Zhao ${ }^{2, \dagger}$ and Jiahai Yuan ${ }^{2, *}$}

1 School of Electrical \& Electronic Engineering, North China Electric Power University, Chang Ping District, Beijing 102206, China; E-Mail: 50101453@ncepu.edu.cn

2 School of Economics and Management, North China Electric Power University, Chang Ping District, Beijing 102206, China; E-Mails: zwh3702@163.com (W.Z.); zchh21@126.com (C.Z.)

$\dagger$ These authors contributed equally to this work.

* Author to whom correspondence should be addressed; E-Mail: yuanjiahai@ncepu.edu.cn; Tel./Fax: +86-10-6177-3091.

Academic Editor: Erik Gawel

Received: 6 December 2014 / Accepted: 4 February 2015 / Published: 17 February 2015

\begin{abstract}
In 2009, the implementation of feed-in tariff (FIT) and attractive public subsidies for onshore wind farms aroused great investment enthusiasm and spurred remarkable development of wind power in China. Meanwhile, rapid learning-by-doing has significantly cut down the cost of wind turbines and the capital cost of wind farms as well. Therefore, it is the right time to examine the appropriateness of the existing FIT policy for wind power in China. In this paper, we employ the analytical framework for levelized cost of electricity (LCOE) to model the generation cost of wind power. Results show that the existing FIT policy is attractive to investors, but serious curtailment and turbine quality issues could make wind power unprofitable. Meanwhile, rapid substantial decreases in the cost of wind power have made it competitive to coal power in 2013, implying that it is possible and necessary to reform the FIT policy for new wind farms. In the future, energy policies for onshore wind power in China could be concentrated on reducing the integration cost, so as to reduce the overall system cost.
\end{abstract}

Keywords: wind power; feed-in tariff (FIT); levelized cost of electricity; China 


\section{Introduction}

Since the promulgation of the Renewable Energy Law in 2006, wind power has reached a stage of rapid expansion in China. During 2006-2009, the cumulative installation of wind power doubled for four consecutive years [1]. In 2009, the newly-added capacity in China was $13.8 \mathrm{GW}$, which exceeded the total of China's capacity installation in the past twenty years and outpaced the scale of the U.S. in the same year. By 2010, the cumulative installation amounted to $44.73 \mathrm{GW}$ and the growth was strong. Presently, wind power has moved into large-scale deployment in China. At the end of 2012, the total installation had reached $75.3 \mathrm{GW}[2]$.

Two factors are behind the rapid growth of wind capacity installation in China. The first is the radical reduction in turbine prices. The second is the national feed-in tariff effective since 2009 for wind power generation. However, the learning-by-doing in China's wind industry has led to discussion and possible revision of the tariff policy. A recent move by China's central government is a notice by the National Development and Reform Commission (NDRC) to lower the tariff levels of the newly-added wind farms after 2015 by $0.02-0.04$ cent/kWh(in Chinese currency, yuan; 1 US\$ $=6.2019$ yuan in 2014). On the one hand, the wind farm developers claim that this curtailment is a serious problem and the wind farms cannot recovery the full investment with the new lowered tariff. On the other hand, the government's public subsidy for renewable energy is not designed to be permanent, so the question is whether now is good time for the government to adjust the tariff levels for wind farms in China.

The purpose of the study is to conduct a detailed economic analysis on the economy of wind power generation in China. We will employ the standard levelized cost of electricity (LCOE) to model wind power generation in China and draw on the policy implications for the government. The remainder of the paper is organized as follows: Section 2 presents the literature review. Section 3 presents the model, data and assumptions of the study. Section 4 reports the results of wind power LCOE. Section 5 presents further discussion on the numerical results. Section 6 concludes with policy implications.

\section{Literature Review}

Globally, feed-in-tariff (FIT) is an effective tool to deploy renewable energy. In the literature many authors have discussed the implementation of FIT in the U.S. and European Community member states like Germany, Spain and Denmark [3,4]. In China many problems emerged along with the rapid growth of wind power and have caught wide attention in both policy and academic circles. Zhao, Hu and Zuo [5] developed an improved dynamic diamond model to understand the status quo of the Chinese wind power industry. Wang [6] firstly identified the success of wind capacity installation and the issue of effective wind generation in China. Liu and Kokko [7] analyzed the development status of wind power in China and concluded that state dominance is closely correlated with overcapacity and future reforms of the tariff policy are necessary as costs and conditions in the sector change over time. Liao et al. [8] analyzed the development of the wind supply chain in China and highlighted the importance of domestic manufacturing of wind turbined, the involvement of private investors and the grid integration infrastructure.

Most recent studies have focused on the identification of barriers, mainly with an institutional analysis perspective ([9-11], among others). Several important barriers are identified. For example, 
Luo, Zhi and Zhang [12] found that the inconsistence between wind farms development and grid planning largely leads to the constraints of grid integration. Zhao et al. [10] found that the inflexibility of the feed-in tariff and the lack of grid integration code are among the key barriers. Zhang, Andrews-Speed and Zhao [13] concluded that the mismatch between energy policy and industrial policy is among the key institutional barriers to sustainable wind power development. $\mathrm{Wu}$, Sun and $\mathrm{Du}$ [11] found that the existing incentive structure for generators and grid companies aggravates the imbalance between capacity and utilization. Whatever the barriers are, they ultimately contribute to the curtailment of wind power. According to the statistical data of CWEA, in 2011 the average curtailment rate was 17\% and the wasted electricity was $6 \mathrm{TWh}$; in 2012 the curtailment was worse and the waste amounted to $20 \mathrm{TWh}$, or $20 \%$ of the total wind power generation [1]. The quality issues of wind turbines and their main components are also documented in literature [13,14]. An interesting question here is why wind developers are willing to develop more wind farms even under serious curtailment conditions. An econometric test by Lam et al. [15] indicated that financial assistance, inexpensive transmission access, cost decline and high feed-in tariff (FIT) are the most important microeconomic drivers. Therefore, since 2009 when NDRC reformed the concession bidding procedure and introduced a regionalized FIT policy for wind power, its growth has been accelerated substantially [16]. However, few authors have addressed the effectiveness of the FIT policy in China with the only exception of Hu et al. [17], whose finding is that the financial burden will rise in the long run if technical efficiency does not improve. The mass production of wind power capacity will require larger subsidies and challenges the sustainability of the FIT policy. Besides, Hong and Möller [18] appraised the feasibility of China's 2020 offshore wind power target and concluded that the bidding price is much lower than its levelized production cost and is thus detrimental to the target. Their study also confirmed the importance of tariff policies in wind power development.

\section{Methods}

\subsection{LCOE Model}

The economic feasibility of a power generation project can be evaluated by various methods, but the LCOE is the most frequently used one when comparing electricity generation technologies or considering grid parities for emerging technologies ([19-21]; among others). Therefore, in this paper we use LCOE to appraise the wind power FIT policy in China. Methods for calculating the LCOE vary by application and definition [22]. In this paper, we employ the analytical framework proposed by E3 [23]. The E3 model is based on a detailed representation of generator's cash flows that includes technology and fuel characteristics, operation and maintenance cost, pollutant control and emissions cost and incurred taxes. To the best of our knowledge, it is the first conducted LCOE analysis for various coal and gas generation technologies in China. In this way, our quantitative results for wind power can be directly compared with those of fossil power and shed insights on the national energy policy in China.

The expenses and sales revenues that occur in a future time have to be accounted for the present time value of money, in using a life-cycle technique to estimate the LCOE. This is done by employing discounted cash flow (DCF) techniques, i.e., by calculating the present value of the cash flows with a discount rate, $r$. In this context, the LCOE is determined when the present value of the sum of the 
discounted revenues is equivalent to the discounted value of the sum of the costs during the economic lifetime of the system, $\mathrm{N}$ years, i.e.:

$$
\sum_{n=0}^{N} \frac{\operatorname{Re} \text { venues }_{n}}{(1+r)^{n}}=\sum_{n=0}^{N} \frac{\text { Cost }_{n}}{(1+r)^{n}}
$$

Thus, the Net Present Value (NPV) of the project is zero, i.e.:

$$
N P V=\sum_{n=0}^{N} P V=0
$$

Therefore the LCOE is the average electricity price needed for a NPV of zero when performing a DCF analysis, so that an investor would break even and so receive a return proportional to the discount rate of the investment. The sum of the present values of the $L C O E_{n}$ multiplied by the energy generated annually $\left(E_{n}\right)$, should be equal to the sum of the present values of the costs of the project, i.e.:

$$
\sum_{n=0}^{N} \frac{\left(L C O E_{n}\right) \times\left(E_{n}\right)}{(1+r)^{n}}=\sum_{n=0}^{N} \frac{\operatorname{Cos}_{n} s_{n}}{(1+r)^{n}}
$$

Assuming a constant annual value for the LCOE, we can write:

$$
L C O E=\left(\sum_{n=0}^{N} \frac{\operatorname{Costs}_{n}}{(1+r)^{n}}\right) /\left(\sum_{n=0}^{N} \frac{E_{n}}{(1+r)^{n}}\right)
$$

According to Equation (4), the LCOE equals the sum of all the discounted costs incurred during the lifetime of the project divided by the units of discounted energy produced. It should be noted that the summation calculation starts from $n=0$ to include the initial cost of the project at the beginning of the first year, which should not be discounted. Alternatively, the initial cost could be annualized in the entire life-time of the project:

$$
L C O E=\left(\sum_{n=1}^{N} \frac{\left(\text { CAPEX }_{n}+\text { OPEX }_{n}+T A X_{n}\right)}{(1+r)^{n}}\right) /\left(\sum_{n=1}^{N} \frac{\left(C \times H \times\left(1-o_{u}\right)\right)_{n}}{(1+r)^{n}}\right)
$$

where $C A P E X_{n}$, is the annual value of the initial capital expenditure; OPEX $X_{n}$ is the annual operation expenditure, $T A X_{n}$ is the annual tax; $C$ is the installed capacity; $H$ is the annual utilization hours; $o_{u}$ is the own usage rate; $N$ is the service life of the plant; and $r$ is discount rate.

\subsection{Variables and Factors}

We calculate LCOE by evaluating energy production and costs from construction and operations. The following variables are the principal inputs for calculating LCOE:

- Capital expenditure (CAPEX): the costs to build the wind farm, including wind turbine costs (subject to cost reduction by learning-by-doing), land costs, construction costs, grid connection costs, financial costs and others.

- Financial variables: including own capital ratio, loan interest rate and load period, after-tax internal return rate (IRR), service lifetime, residual value of the project when decommissioning, and deprecation rate. Financial variables have a direct impact on calculating the CAPEX, 
which consists of three components: the annual depreciation of the project, the annual repayment of loan and the incurred interests, and the annual return requirement of own capital.

- Operating expenditure (OPEX): ongoing costs to operate and maintain the plant, including maintenance costs, labor costs, insurance costs and other fixed costs.

- Capacity factor: the fraction of average power generated over the long-term divided by the nameplate power. For wind farms, this factor is calculated by using annual utilization hours divided by $8760 \mathrm{~h}$.

- Tax and policy inputs: including income tax, value added tax, land use tax, urban construction tax and education surcharge, according to the national tax codes which are valid to wind power projects.

- Discount rate: the risk-adjusted opportunity-cost of capital.

\subsection{Parameterization and Assumptions}

\subsubsection{Capital Expenditure (CAPEX)}

The total investment of a wind farm includes equipment costs, land costs, grid connection costs, design \& construction costs, and other miscellaneous expenses. Generally wind turbines account for about $70 \%-80 \%$ of the total investment. In recent years, the enhanced capacity of domestic manufacturing for wind turbines has resulted in a continuous decline in wind turbine prices, which is largely due to China's successful industry policy promoting the manufacture of equipment for the energy sector [24].

Since 2007, the unit price of a mainstream 1.5 MW-sized wind turbine has decreased from 6,700 yuan/KW at the beginning of 2007, to 6,300 yuan/KW in 2008, and to 3,200 yuan/KW in 2012. Empirical studies using learning curve models showed that the learning rate of wind turbine in the early period (covering 2003-2007) ranged around 4.1\%-4.3\% [25] while in the more recent period (2008-2013) it could be above $12 \%$ [26]. We assume that the decreasing learning rate series ranges between $6 \%$ and 8\% during 2013-2015 and 4\%-6\% during 2015-2020, and that the technology becomes fully mature after 2020; we also assume that the other investment components remain unchanged, and we thus obtain the total investment cost of a typical 100-MW wind farm at various years (Table 1).

Table 1. The total investment of a 100-MW wind farm in China commissioned at various years.

\begin{tabular}{ccccc}
\hline Cost component & $\mathbf{2 0 0 9}$ & $\mathbf{2 0 1 3}$ & $\mathbf{2 0 1 5}$ & $\mathbf{2 0 2 0}$ \\
\hline Wind turbine (yuan/KW) & 6300 & 3200 & 2900 & 2700 \\
Turbine cost (million yuan) & 630 & 320 & 290 & 270 \\
Land cost (million yuan) & 57 & 57 & 57 & 57 \\
Construction cost (million yuan) & 85 & 85 & 85 & 85 \\
Grid connection cost (million yuan) & 17 & 17 & 17 & 17 \\
Tax and other miscellaneous expenses & 11 & 11 & 11 & 11 \\
Total CAPEX $($ million yuan) & 800 & 490 & 460 & 440 \\
Average CAPEX (yuan/KW) & 8000 & 4900 & 4600 & 4400 \\
\hline
\end{tabular}




\subsubsection{Financial Factors}

According to the convention of electric power sector, the financial factors for a wind farm are provided in Table 2. The own capital ratio is $20 \%$ and the remaining $80 \%$ is loans. The interest rate of loan has stabilized at $6 \%$ in recent years and the basic return requirement of power sector investors is $8 \%$. The designed service life of a wind farm is 20 years. Considering the existence of quality issues, we also assume a shorter service life of 15 years for sensitivity analysis. The standard deprecation period is 15 years; similar to the assumption on service life, a shorter depreciation period of 10 years is also assumed accordingly. Regarding the residual value of the project, a standard parameter of $5 \%$ of initial investment is used in the power sector.

Table 2. Financial factors of a wind power project.

\begin{tabular}{cc}
\hline Financial parameter & Parameter \\
\hline Own capital ratio & $20 \%$ \\
Loan period (years) & 15 \\
Loan interest rate & $6 \%$ \\
After-tax internal rate of return & $8 \%$ \\
Weighted average cost of capital & $6.8 \%$ \\
Service life (years) & $15-20$ \\
Deprecation years & $10-15$ \\
Residual value rate & $5 \%$ \\
\hline
\end{tabular}

\subsubsection{O\&M Expenditure (OPEX)}

The OPEX of wind farms includes insurance costs, maintenance costs, salaries and benefits and other fixed or semi-fixed O\&M costs (office expenses, transportation expenses, etc.). In our study, the OPEX parameters are determined based on the conventions of the electric power sector or field survey data. According to the conventions of the electric power industry, the insurance rate is $0.25 \%$ of the total investment. According to the design standard of wind farms, the maintenance rate (including parts and materials, repair and labor costs for the maintenance) is between $1.5 \%$ and $2 \%$ [27]. However, according to our survey, the actual maintenance rate is much higher than the standard values because of the poor quality of the equipment. Therefore, we assume a standard rate of $2 \%$ and a much higher rate of $4 \%$ for sensitivity analysis. For standard staffing, our survey of several wind farms shows that a typical wind farm e one frontline worker for every 10MW of capacity and the ratio between frontline and administrative staff is 10:2. This standard leads to a staff of 12 workers for a $100 \mathrm{MW}$ wind farm. The average annual salary is set as 80,000 yuan/yr in 2009, which is based upon our survey. A standard benefit factor of $60 \%$ is added to calculate the total labor cost. Besides, based upon the average salary growth in the electric power industry in the last decade, an annual growth rate of $6 \%$ for real salaries is assumed. The parameters for other fixed cost and its escalator is set based on CREEI [27]. Table 3 provides all the OPEX parameters. 
Table 3. The OPEX parameters of a 100-MW wind farm in China.

\begin{tabular}{cc}
\hline OPEX component & Parameter \\
\hline Insurance rate $(\%)$ & $0.25 \%$ \\
Maintenance rate $(\%)$ & $2 \%-4 \%$ \\
Employee (persons/farm) & 12 \\
Average annual salary (yuan/yr) & 80000 \\
Salary benefit adder $(\%)$ & $60 \%$ \\
Real salary growth $(\% / \mathrm{yr})$ & $6 \%$ \\
Other fixed cost (yuan/KWh) & 0.02 \\
Cost escalator $(\% / \mathrm{yr})$ & $2 \%$ \\
\hline
\end{tabular}

\subsubsection{Capacity Factor and Own Use Ratio}

Capacity factor is the most important parameter for calculating the annual electricity generation. The wind resource conditions vary because of the wide geographic distribution of the Chinese territory. In 2009, the National Development and Reform Commission (NDRC) released NDRC Pricing Regulation 1906[16], which divided China's onshore wind resource into four categories and each category has a different benchmark feed-in tariff. According to the regulation, the better the wind resource is, the higher the operation hours are, and accordingly the lower the regional FIT is. The regional benchmark FIT is set based upon the assumption that the commissioned wind farm can operate at full utilization rate with no restrictions. However, the actual operation conditions are much worse than expected. In 2011 the national average operation hours of wind farms was 1920; while in 2012 the average was lowered to $1890 \mathrm{~h}$ [28]. In East Inner Mongolia and Jilin provinces, the curtailment rate was as high as $50 \%$ during the winter heating season. In West Inner Mongolia, the Jiuquan region of Gansu Province and the Zhangjiakou region of Hebei Province, the curtailment rate was more than $20 \%$ (Table 4). One point that deserves careful notice is that in all the regions with serious curtailment, the local electricity demand is weak and trans-regional transmission capacity is insufficient to transport the wind energy to load centers. On the contrary, in category IV regions like Shanghai and Yunnan Province, etc. where wind resources are not very good, the annual operation can reach $2300 \mathrm{~h}$ or more, largely because of strong local demand.

The other operation parameter that is closely relevant to electricity sales is the own use ratio. According to our survey, the own use ratio in a typical wind farm equipped with automatic generation control and other reactive power compensation and harmonic suppression devices is $2 \%$, implying that the wind farm will consume $2 \%$ of its power generation for operating itself. 
Table 4. Planned and actual operation hours of wind farms in different resource zones in China.

\begin{tabular}{|c|c|c|c|c|}
\hline $\begin{array}{l}\text { Resource } \\
\text { zone }\end{array}$ & $\begin{array}{c}\text { Benchmark FIT } \\
(\text { yuan/kWh })\end{array}$ & Administrative areas included & $\begin{array}{c}\text { Expected } \\
\text { operation } \\
\text { hours }\end{array}$ & $\begin{array}{c}\text { Actual } \\
\text { operations } \\
\text { hours }\end{array}$ \\
\hline Category I & 0.51 & $\begin{array}{l}\text { Inner Mongolia Autonomous Region except: Chifeng, } \\
\text { Tongliao, Xing'anmeng, Hulunbeier; Xinjiang Uygur } \\
\text { Autonomous Region: Urumqi, Yili, Karamay, Shihezi }\end{array}$ & 2500 & 1500 \\
\hline Category II & 0.54 & $\begin{array}{l}\text { Hebei Province: Zhangjiakou, Chengde; Inner Mongolia } \\
\text { Autonomous Region: Chifeng, Tongliao, Xing'anmeng, } \\
\text { Hulunbeier; Gansu Province: Zhangye, Jiayuguan, Jiuquan }\end{array}$ & 2300 & 1800 \\
\hline Category III & 0.58 & $\begin{array}{l}\text { Jilin Province: Baicheng, Songyuan; Heilongjiang Province: } \\
\text { Jixi, Shuangyashan, Qitaihe, Suihua, Yichun, Daxinganling } \\
\text { Region, Gansu Province except: Zhangye, Jiayuguan, Jiuquan, } \\
\text { Xinjiang Autonomous Region except: Urumqi, Yili, Changji, } \\
\text { Karamay, Shihezi, Ningxia HuiAutonomous Region }\end{array}$ & 2100 & 1900 \\
\hline Category IV & 0.61 & Other parts of China not mentioned above & 1900 & 2300 \\
\hline
\end{tabular}

\subsubsection{Tax and Policy Inputs}

According to the tax codes of China, the rates of various types of tax and related policies are summarized in Table 5. First of all, wind farms enjoy full exemption of income tax for the first three years of operation, then half exemption for the second three years. Otherwise a preferential income tax rate of $15 \%$ is effective. For value added tax, the regular tax rate is $17 \%$ in China while wind farms enjoy a half exemption (8.5\%) with intermediate costs and fixed asset investment as deductable items. The property tax for wind farms (with the value of land and office buildings as the tax base) is $1.2 \%$ with a $30 \%$ exemption. The effective land use tax is $2 \mathrm{yuan} / \mathrm{m}^{2}$ for non-cultivated land while a typical $100-\mathrm{MW}$ wind farm occupies a land area around $5 \mathrm{~km}^{2}$, implying that the total lump sum payable land use tax is 10 million yuan. There are also two additional taxes, the urban construction tax with rate of $5 \%$ and an education surcharge with a rate of $4 \%$, with payable value added tax as their taxable base.

Table 5. Tax and policy inputs.

\begin{tabular}{ccc}
\hline Types of tax & Tax rate & Tax base \\
\hline Income tax & $\begin{array}{c}\text { Full exemption of the first three } \\
\text { operation years, and half } \\
\text { exemption of the second three } \\
\text { operation years, otherwise } 15 \%\end{array}$ & $\begin{array}{c}\text { Taxable income } \\
\text { Value added tax }\end{array}$ \\
\hline Property tax & $\begin{array}{c}\text { Annual income deduced by } \\
\text { intermediate cost and fixed } \\
\text { assets investment }\end{array}$ \\
\hline & $1.2 \%$ with $30 \%$ exemption & $\begin{array}{c}\text { Land and building assets } \\
\text { (about } 10 \% \text { of the total } \\
\text { investment) }\end{array}$ \\
\hline
\end{tabular}


Table 5. Cont.

\begin{tabular}{ccc}
\hline Types of tax & Tax rate & Tax base \\
\hline Land use tax (yuan $\left./ \mathrm{m}^{2}\right)$ & $\begin{array}{c}2 \text { yuan } / \mathrm{m}^{2} \text { for non-cultivated land; } \\
\text { or } 12 \text { yuan } / \mathrm{m}^{2} \text { for cultivated land }\end{array}$ & Occupied and area (lump sum) \\
\hline Land area (100-MW wind farm) & $5 \mathrm{~km}^{2}$ & Payable value added tax \\
\hline Urban construction tax & $5 \%$ & Payable value added tax \\
\hline Education surcharge (central government) & $3 \%$ & Payable value added tax \\
\hline Education surcharge (local government) & $1 \%$ & \\
\hline
\end{tabular}

\subsubsection{Discount Rate}

The discount rate $r$ reflects the risk-adjusted opportunity-cost of capital. Many analysts assume a single "social resource cost" as the discount rate for any technology in their LCOE calculation, in order to compare technologies without influence from what may be seen as judgments from financial markets that are irrelevant to the technologies [29]. In our study, we use the minimum internal return rate requirement of power projects in China $(8 \%)$ as the discount rate.

\section{Results}

\subsection{Scenario Setting}

Because our main interest is to find out whether the regionalized FIT policy issued in 2009 is effective, the following numerical scenarios are used for analysis and comparison:

- A typical 100-MW wind farm commissioned in 2009, with consideration of variations in annual operation hours, turbine quality and service life;

- A typical 100-MW wind farm commissioned in 2013;

- A hypothetica 1100-MW wind farm commissioned in 2015 and 2020, with consideration of the learning effect in wind turbine technology improvement.

For the typical 2009 and 2013 wind farm, we will probe not only differentiated LCOE levels under baseline IRR of $8 \%$, but also the expected internal rates of return under the regionalized FIT levels, according to existing policy.

\subsection{Results}

Table 6 provides the estimated LCOE results for a typical wind farm commissioned in 2009 and 2013. Given the unit investment level at 8,000 yuan per KW capacity installation in 2008 (lead time 1 year), under the planned annual operation hours ranging between 2,500 and 1,900, the standard service life of 20 years and standard maintenance rate, the calculated LCOE of wind power ranges between 0.45 and 0.59 yuan per KWh. In 2013, because the rapid learning-by-doing in wind turbine manufacture has effectively reduced the unit investment level to 4,900 yuan per KW capacity installation, the LCOE was between 0.31 and 0.40 yuan per KWh. Accordingly, we estimate the IRR levels under the existing FIT policy and find that under expected annual operation hours without curtailment, the wind farm commissioned in 2009 can enjoy an IRR ranging between $22 \%$ and $13 \%$. 
Moreover, for the wind farm commissioned in 2013 , the IRR reaches as high as $89 \%-73 \%$, which is very extravagant given the scarcity of public funds to promote renewable energy in China (Table 7). Another point deserving attention is that for a typical 2009 wind farm located in a category I region, with shorter operation (1900 h) and service life (15 years), as well as high maintenance rate (4\%), its LCOE will be 0.73 yuan/KWh. This level is significantly higher than the effective FIT of 0.51 yuan/KWh, implying that such a wind farm is actually losing money. However, under the same situation, the LCOE of a wind farm commissioned in 2013 is 0.48 yuan/KWh, implying that with rapid decrease in investment expenditure a wind farm can be profitable even under serious curtailment and shorter than designed service life.

Table 6. Estimated LCOEs of wind power in China, 2009 and 2013 cases.

\begin{tabular}{|c|c|c|c|c|c|c|c|c|c|c|}
\hline \multirow{2}{*}{ Parameters/Results } & \multicolumn{5}{|c|}{2009} & \multicolumn{5}{|c|}{2013} \\
\hline & S1 & S2 & S3 & S4 & S5 & S1 & $\mathbf{S 2}$ & S3 & S4 & S5 \\
\hline Unit investment (yuan/KW) & 8000 & 8000 & 8000 & 8000 & 8000 & 4900 & 4900 & 4900 & 4900 & 4900 \\
\hline Annual operation (hours) & 2500 & 2300 & 2100 & 1900 & 1900 & 2500 & 2300 & 2100 & 1900 & 1900 \\
\hline Service life (years) & 20 & 20 & 20 & 20 & 15 & 20 & 20 & 20 & 20 & 15 \\
\hline Depreciation (years) & 15 & 15 & 15 & 15 & 10 & 15 & 15 & 15 & 15 & 10 \\
\hline Maintenance rate & $2 \%$ & $2 \%$ & $2 \%$ & $2 \%$ & $4 \%$ & $2 \%$ & $2 \%$ & $2 \%$ & $2 \%$ & $4 \%$ \\
\hline $\begin{array}{l}\text { Wind power LCOE } \\
\text { (yuan/KWh) }\end{array}$ & 0.45 & 0.49 & 0.53 & 0.59 & 0.73 & 0.31 & 0.33 & 0.36 & 0.40 & 0.48 \\
\hline $\begin{array}{c}\text { Benchmarking desulfurized coal } \\
\text { power price (yuan/KWh) }\end{array}$ & $0.25-0.3$ & $0.31-0.43$ & 0.41 & $0.45-0.49$ & - & $0.254-0.3$ & $0.35-0.4$ & 0.4 & $0.44-0.46$ & - \\
\hline
\end{tabular}

Note: ${ }^{1}$ The price data of coal power are sourced from NDRC [30]; ${ }^{2} \mathrm{We}$ assume an extreme scenario (S5) in which quality issues lead to both high maintenance cost and shorter service life based on SERC [14].

Table 7. Estimated IRRs of wind power under the existing FIT policy, 2009 and 2013 cases.

\begin{tabular}{ccccc}
\hline $\begin{array}{c}\text { Resource } \\
\text { zone }\end{array}$ & $\begin{array}{c}\text { Benchmark feed-in } \\
\text { tariff (yuan/kWh) }\end{array}$ & $\begin{array}{c}\text { Expected annual } \\
\text { operation (hours) }\end{array}$ & $\begin{array}{c}\text { Expected IRR in 2009 } \\
\text { capital investment }\end{array}$ & $\begin{array}{c}\text { Expected IRR in 2013 } \\
\text { capital investment }\end{array}$ \\
\hline Category I & 0.51 & 2500 & $22 \%$ & $89 \%$ \\
Category II & 0.54 & 2300 & $19 \%$ & $85 \%$ \\
Category III & 0.58 & 2100 & $18 \%$ & $84 \%$ \\
Category IV & 0.61 & 1900 & $13 \%$ & $73 \%$ \\
\hline
\end{tabular}

In China the feed-in tariff for wind power is set based upon the desulfurized coal power price plus a certain subsidy. In the last row of Table 6 , the benchmarking desulfurized coal power prices for plants operated in the same wind resource region are provided to compare the competiveness of wind power. In 2009, the coal power price in the Xinjiang and Inner Mongolia regions (Category I) was $0.25-0.3$ yuan/KWh, while the wind power tariff is 0.51 yuan/KWh, $0.2-0.25$ yuan higher than coal power. For Category II regions (Hebei and West Inner Mongolia, for example), the difference (or subsidy) is about 0.15 yuan; for Category III regions (Jilin Province, for example) and Category IV (Jiangsu and Zhejiang Provinces, for example) the difference is between 0.15-0.17 yuan. With the subsidy provided in the FIT, the wind farm can enjoy an IRR between $13 \%$ and $22 \%$. However, with radical decrease in wind turbine price, in 2013 the LCOEs of wind power are approaching (in I and II regions) or well below (in III and IV regions) coal power prices. Furthermore, we project wind power's LCOEs in 2015 and 2020, under the assumption of a decreasing learning rate, from $6 \%$ during 2013-2015 to 4\% during 2015-2020 (Table 8). Results show that the decrease in investment 
expenditure will have little impact on LCOE in the future; but annual operation hours, service life and maintenance cost will continue to produce significant effects.

Table 8. Estimated LCOE levels of wind power in China, 2015 and 2020 cases.

\begin{tabular}{|c|c|c|c|c|c|c|c|c|c|c|}
\hline \multirow{2}{*}{ Parameters/Results } & \multicolumn{5}{|c|}{2015} & \multicolumn{5}{|c|}{2020} \\
\hline & S1 & $\mathbf{S 2}$ & S3 & S4 & S5 & S1 & S2 & S3 & S4 & S5 \\
\hline Unit investment (yuan/KW) & 4600 & 4600 & 4600 & 4600 & 4600 & 4400 & 4400 & 4400 & 4400 & 4400 \\
\hline Annual operation (hours) & 2500 & 2300 & 2100 & 1900 & 1900 & 2500 & 2300 & 2100 & 1900 & 1900 \\
\hline Service life (years) & 20 & 20 & 20 & 20 & 15 & 20 & 20 & 20 & 20 & 15 \\
\hline Depreciation (years) & 15 & 15 & 15 & 15 & 10 & 15 & 15 & 15 & 15 & 10 \\
\hline Maintenance rate & $2 \%$ & $2 \%$ & $2 \%$ & $2 \%$ & $4 \%$ & $2 \%$ & $2 \%$ & $2 \%$ & $2 \%$ & $4 \%$ \\
\hline $\begin{array}{l}\text { Wind power LCOE } \\
\text { (yuan/KWh) }\end{array}$ & 0.29 & 0.32 & 0.35 & 0.38 & 0.46 & 0.29 & 0.31 & 0.34 & 0.37 & 0.45 \\
\hline
\end{tabular}

\section{Discussion}

\subsection{The Logic of Wind Power Policies in China}

The successes of wind power policy in China can be summarized as: (1) a strong political motive; (2) the implementation of the Renewable Energy Law and clear development targets declared in various planning documents; (3) the competition in wind concession projects to reduce the price of wind power; (4) the FIT policy and a special fund to sustain it; (5) the localization of wind turbine manufacturing ([10,31]).

Ever since the promulgation of the Renewable Energy Law in 2006, a series of comprehensive planning steps for renewable energy or specific planning for wind power have been formulated and put into implementation, which provide a clear signal to wind power investors in China. The most recent update in specific planning was issued by the Ministry of Science and Technology in April of 2012, proposing that the total installation of wind power should reach $100 \mathrm{GW}$ by 2015 [32]. Soon after it, the State Council issued a comprehensive plan for the strategic emerging industries, stating that the newly-added wind power capacity should reach 70GW during 2011-2015. Furthermore, the plans by the National Energy Administration issued in 2012 also proposed concrete development targets, pathways and priorities for the coming five years [33].

Regarding the tariff policy, China has stipulated different tariff mechanisms at different periods to promote the healthy development of wind power. In the beginning of the 1990s when wind power was at the initial stage in China, most of the investment on wind turbines was sourced from foreign aid, while tariffs for wind power was set at low levels comparable to local coal prices. Since 1998, the pricing policy for wind power was approved by the local governments and therefore the tariff levels have varied among different regions. Then from 2003, concession bidding price was introduced to promote the development of large-scale wind farms. Therefore, bidding prices and government mandate prices coexisted during 2003-2006, until in 2006 the government mandate pricing mechanism was abolished. Though bidding pricing effectively lowers the cost of wind power in China, the problem is that it requires extensive administrative input and results in utterly different tariff levels for wind farms developed at different regions and at different times. To simplify the tariff policy, in 2009 
the National Development and Reform Commission issued the policy of regionalized benchmarking pricing for wind power [16], which stipulates four different tariff levels according to the resource conditions. The benchmarking FIT policy provides strong economic incentives to wind power investors in China.

Tax policy also plays essential role in the domestic manufacture of wind turbines in China and contributes to the wind power cost reductions. During the initial stage of wind power development, an exemption from import duty was implemented to support the capacity installation. Then in 2008, the Ministry of Finance issued a tax policy, providing import duty exemption on the key components of wind turbines, instead of the entire wind turbines [34]. For turbine manufacturers, public subsidies are also provided to promote the localized production of new turbine models. In the end of 2008, State Administration of taxation issued a policy to provide a preferential VAT tax policy for wind farms, as well as full exemption of corporate income tax during the first three years of operation and half exemption during the second three years [35].

\subsection{Implication of the Numerical Results}

The numerical analysis on the LCOE can provide a different perspective on renewable energy policy in China. Although existing wind policies have been effective in promoting the scale-up of domestic production and capacity installation, the focus on installed capacity rather than generation, the focus on production scale of wind turbine rather than quality, and the focus on industry policy (to promote economic growth) rather than energy policy (to promote renewable penetration), have frequently been criticized in the literature ([11,14]). The LCOE results reveal somewhat opposite evidence.

Our study rightly indicates that because of the attractive FIT policy that stimulates wind power investment, the industrial policy that promotes the domestic manufacture of wind turbines and the positive interaction between cumulative production (installation) and technology learning, the LCOE of wind power is reduced rapidly and effectively making wind power commercially competitive with coal power in China. Though grid integration and effective utilization of the installed capacity are important in the sustainable development of wind power and other renewable energy as well, technology learning and cost reduction are certainly the top policy priorities in the beginning. Morthorst proposed a framework for evaluating the process of wind power development, including investment certainty, effectiveness, efficiency, market competition, and administrative demands [36]. $\mathrm{Hu}$ et al. [17] narrowed down the framework to four indicators, including technology, wind resources, administration, and time/space frame. Using their framework as the evaluation metrics, the numerical LCOE results clearly indicate that wind power policy until recently was actually very successful in China, especially in the investment certainty, technology learning and cost reduction.

Furthermore, the analysis also indicates that radical reforms should be made in the future wind policy. Currently the subsidy for wind power and other renewable energy is sourced from two parts, the special fund of the central government, and the surcharge in the retail tariff of electricity [37]. The first part is subject to annual budget restrictions, while the second part is collected from various electricity consumers around the country. Since the issue of the Renewable Energy Law in 2006, China began to collect a surcharge on the electricity tariff with an initial standard of 0.1 cent per KWh. With the increase in the installed capacity and generation of renewable energy, the demand for 
subsidies is increasing quickly in China. As a response, the government has raised the surcharge level several times, firstly from 0.1 cent to 0.4 cent, then from 0.4 cent to 0.8 cent, and recently from 0.8 cent to 1.5 cent [38]. However, the growth of the renewable energy fund is unable to keep pace with increasing subsidy demands. It is estimated that in 2009 the gap was 1.3 billion yuan, while in 2011 the gap soared to more than 10 billion yuan. According to the renewable energy development plan during the 12th FYP period, by the end of 2015 the subsidy requirement will amount to at least 100 billion yuan, while on the supply side the fund can support at most 50 billion yuan. Therefore the government is finding itself in a dilemma: increasing the surcharge level and assuming the side-effects of high tariffs, or keeping the surcharge level unchanged and taking the risk of slow-down in renewable deployment.

The rationale for providing subsidies to renewable energy with a FIT scheme is that in the early development stages renewable energy is much more expensive than traditional energy. Hopefully, the scale-up and learning-by-doing will cut the cost down and render it competitive with traditional energy. Hence the subsidy policy is designed to function only for a certain period. When renewable energy is becoming commercially viable, it is the time to stop the subsidy and have the market work by itself [39]. If China continues to provide generous subsidies to onshore wind power, the risks are as follows. First of all, the consumers' willingness to accept renewable energy will be reduced. If consuming renewable energy always means more expenditure, the consumers may be reluctant to using it. Secondly, for the national economy, the cost of electricity service will also be high and push up the production cost. Thirdly, the opportunity for other nearly-commercialized renewable energy sources such as offshore wind power and solar PV will be deprived of funds. Last but not the least important, unnecessary subsidies are not only inefficient in an economic sense, but also a waste of public good. As a result, the consumers, the renewable energy industry and the entire national economy will suffer. A wiser way is to reduce or gradually cancel the subsidy for newly commissioned onshore wind power projects by introducing a sunset mechanism. Then more resources can be provided to support offshore wind power and solar PV.

It should also be noticed that even though onshore wind power is competitive with coal power at the LCOE level, its system cost could still be higher than that of coal power. To overcome the deficits of an LCOE comparison Joskow [40] emphasized that the economic evaluation of any power generating technology should consider both costs and value. Variable renewable energies are economically efficient if their LCOE (marginal costs) equal their marginal economic value. Moreover, they are competitive if LCOE are equal or below their market value. Ueckerdt et al. [41] developed the idea of Joskow [40] by defining a concept of system LCOE, which can be interpreted as the marginal economic costs of renewable energy and the costs induced by their variability on a system level. Though all power generation technologies induce integration costs, because renewable energies interact differently with the power system, they are much more difficult to integrate especially at high shares. Integration costs are defined as "the additional cost of accommodating intermittent renewable energy like wind and solar" [42]. Wind power would only be economically efficient and competitive without subsidies if its system LCOE is below the average costs of a purely conventional system. Three options are available for reducing the integration cost: firstly, adjusting the residual generation capacities to a mix with lower capital cost; secondly, increasing transmission capacity to neighboring power systems, in particular if those power systems have different renewable energy sources; and thirdly, any measures that increase the flexibility of the power system. 
China has formulated a target of $15 \%$ non-fossil primary energy by 2020 and recently announced another ambitious 20\% non-fossil primary energy target by 2030 [43]. Wind power is certainly a promising contributor for realizing these targets. Therefore, when the LCOE of wind power is already competitive to coal power, in the future it is important for the Chinese government to concentrate on decreasing the system cost of wind power. The following measures are especially suitable in China: providing better conditions for grid-access; constructing enhanced transmission channels, especially trans-regional transmission lines [44,45]; building more reserve capacity to enhance the flexibility of the system [46,47]; and establishing fair and renewable-friendly dispatch rules. In such a facilitating environment, onshore wind power can overcome the market barriers and becomes fully economically efficient and competitive in China.

The development pattern of wind power also closely relates with its system LCOE. Unlike in many developed countries where wind power is mostly developed in a distributed way, in China wind power is developed in a concentrated way. Until presently, most wind farms in China are located in western or northern resource-abundant regions and then transmission systems are built to transmit the electric power to the demand centers. This development pattern certainly has its own advantages in that it cannot only accelerate the scale-up of capacity installation promptly, but also ease the coordination difficulty between renewable development and grid planning. The other advantage is that it fits in the existing power grid infrastructure and operation conventions well. Therefore, we argue in this paper that the concentrated development pattern actually helps cut down the LCOE of wind power in China. But on other side, the system LCOE is high because of additional transmission system, longer transmission distances and extra reserve capacity requirement. However, below certain generation share and under certain generation mix conditions, integrating wind or solar power into the distributed power system doesn't necessarily result in extra integration costs. In the future, wind power can be developed in a concerted combination of concentrated and distributed way in China.

\section{Conclusions and Policy Implications}

By employing an analytical framework with detailed precision, the LCOE of wind power in China is estimated in this paper. Numerical results show that the FIT levels set in 2009 is appropriate and can provide strong incentives for investors to develop wind farms, which largely explains why wind power has been experiencing a boom in China since 2009. Results based on the data of wind farms commissioned in 2013 also show that the LCOE of wind power has lowered substantially and wind power has already become economically competitive to coal power in China. In contrast to many authors who express concerns over the failures of wind power policy in China, we actually obtain positive evidence of its success. The clear and ambitious plan for developing wind power, the industrial and tax policy to promote domestic manufacturing of wind turbines, the former bidding process to introduce competition and act as a price discovery mechanism as well, and the attractive FIT scheme to attract investment and promote scale-up in capacity installation, jointly lead to substantial learning-by-doing in turbine manufacturing and radical decrease in the cost of wind power generation. Meanwhile, the analysis also clearly indicates that if curtailment and quality issues are not to be addressed properly, the sustainability of wind power development in China will be endangered. 
According to our numerical analysis, wind power has already become competitive in China. The implication is that the policy package for wind power should be shifted from the LCOE to the integration cost and concentrate on the decrease of system LCOE. The following policy implications can be abstracted from the study.

- The focus of industry policy for wind turbines should be transformed from scale to quality and innovation. The government can redesign the policy to promote independent technology innovation, which can provide additional technology learning in the future. Meanwhile a national quality standard system should be established to promote the improvement in turbine and components quality. In this way, the LCOE of wind power can be further cut down.

- Most focused policies can be designed and implemented to lower the other part of system LCOE, or the integration cost for wind power. Concrete technical codes for grid-access, enhanced transmission channel (especially trans-regional transmission lines to facilitate final utilization), more flexibility in the reserve capacity of the power system, harmonized development pattern of both concentrated and distributed ways, and friendly dispatch rules for renewable can further cut down the system cost of LCOE.

- The Chinese government can terminate the subsidies for newly constructed onshore wind projects, or introduce a sunset mechanism to cut down the subsidies. More resources can be provided to improving the grid-access and system operation conditions. The saved public resources can be provided to offshore wind power and solar power to further promote the renewable energy penetration in China.

- A parallel move along with tariff reform is the establishment of market mechanism for large-scale deployment of wind power. The government's priority can focus on: shaping a fair market environment for different generation technologies; coordinating the planning on renewable energy and power grids; and furthering market reform in the power sector.

\section{Acknowledgments}

The authors would like to appreciate the detailed comments of the anonymous reviewers and the kind help of the Editor, which significantly enhance the quality of the paper. The work reported in the paper is funded by Beijing Higher Education Young Elite Teacher Project (YETP0707) and the Fundamental Research Funds for the Central Universities. The usual caveats apply.

\section{Author Contributions}

Jiahai Yuan contributed to the research idea and the framework of this study. Zifa Liu conducted the numerical analysis. Other authors contributed equally to the study.

\section{Conflicts of Interest}

The authors declare no conflict of interest. 


\section{References}

1. Chinese Wind Energy Association (CWEA). Statistics on Wind Power Curtailment in China; Chinese Wind Energy Association (CWEA): Beijing, China, 2012.

2. Chinese Wind Energy Association (CWEA). China Wind Power Capacity Statistics for 2012; Chinese Wind Energy Association (CWEA): Beijing, China, 2013; pp. 1-10.

3. National Renewable Energy Laboratory (NREL). State Clean Energy Policies Analysis (SCEPA) Project: An Analysis of Renewable Energy Feed-in Tariffs in the United States; NREL: Washington, DC, USA, 2009.

4. Stokes, L.C. The politics of renewable energy policies: The case of feed-in tariffs in Ontario, Canada. Energy Policy 2013, 56, 490-500.

5. Zhao, Z.Y.; Hu, J.; Zuo, J. Performance of wind power industry development in China: A Diamond Model study. Renew. Energy 2009, 34, 2883-2891.

6. Wang, Q. Effective policies for renewable energy — The Example of China's Wind Power_Lessons for China's Photovoltaic Power. Renew. Sustain. Energy Rev. 2010, 14, 702-712.

7. Liu, Y.; Kokko, A. Wind power in China: Policy and development challenges. Energy Policy 2010, 38, 5520-5529.

8. Liao, C.; Jochem, E.; Zhang, Y.; Farid, N.R. Wind power development and policies in China. Renew. Energy 2010, 35, 1879-1886.

9. Yang, M.; Patiño-Echeverri, D.; Yang, F. Wind power generation in China: Understanding the mismatch between capacity and generation. Renew. Energy 2012, 41, 145-151.

10. Zhao, X.; Zhang, S.; Yang, R.; Wang, M. Constraints on the effective utilization of wind power in China: An illustration from the northeast China grid. Renew. Sustain. Energy Rev. 2012, 16, 4508-4514.

11. Wu, Z.; Sun, H.; Du, Y. A large amount of idle capacity under rapid expansion: Policy analysis on the dilemma of wind power utilization in China. Renew. Sustain. Energy Rev. 2014, 32, 271-277.

12. Luo, G.-L.; Zhi, F.; Zhang, X. Inconsistencies between China's wind power development and grid planning: An institutional perspective. Renew. Energy 2012, 48, 52-56.

13. Zhang, S.; Andrews-Speed, P.; Zhao, X. Political and institutional analysis of the successes and failures of China's wind power policy. Energy Policy 2013, 56, 331-340.

14. State Electricity Regulatory Committee (SERC). Report on the Regulation of Wind Power Safety. 2011. Available online: http://www.serc.gov.cn/zwgk/jggg/201112/W020120111527586623342.pdf (accessed on 16 December 2013).

15. Lam, J.C.K.; Woo, C.K.; Kahrl, F.; Yu, W.K. What moves wind energy development in China? Show me the money! Appl. Energy 2013, 105, 423-429.

16. National Development and Reform Commission (NDRC). Benchmark Feed-in Tariffs for Wind Power in China; NDRC: Beijing, China, 2009.

17. Hu, Z.; Wang, J.; Byrne, J.; Kurdgelashvili, L. Review of wind power tariff policies in China. Energy Policy 2013, 53, 41-50.

18. Hong, L.; Möller, B. Feasibility study of China's offshore wind target by 2020. Energy 2012, 48, $268-277$. 
19. Cory, K.; Schwabe, P. Wind levelized cost of energy: A comparison of technical and financing input variables. In National Renewable Energy Lab Office of Energy Efficiency and Renewable Energy; NREL: Washington, DC, USA, 2010.

20. National Renewable Energy Laboratory (NREL). Simple levelized cost of energy (LCOE) calculator documentation. 2010. Available online: http://www.nrel.gov/analysis/lcoe documentation.html (accessed on 16 December 2013).

21. Branker, K.; Pathak, M.J.M.; Pearce, J.M. A review of solar photovoltaic levelized cost of electricity. Renew. Sustain. Energy Rev. 2011, 15, 4470-4482.

22. Levitt, A.C.; Kempton, W.; Smith, A.P.; Musial, W.; Firestone, J. Pricing offshore wind power. Energy Policy 2011, 39, 6408-6421.

23. Energy+ Environmental Economics (E3). Generation Cost Model for China; E3: San Francisco, CA, USA, 2012.

24. Liang, F.; Chen, L. Analysis of investment benefit based on benchmark tariff for wind power project. Energy Technol. Econ. 2012, 24, 21-25.

25. Qiu, Y.; Anadon, L.D. The price of wind power in China during its expansion: Technology adoption, learning-by-doing, economies of scale, and manufacturing localization. Energy Econ. 2012, 34, 772-785.

26. Di, Y.; Cui, X.; Liu, X. The impact of technology innovations on cost of China's wind power industry. J. Quant. Tech. Econ. 2012, 3, 1-11.

27. China Renewable Energy Engineering Institute (CREEI). Wind Farm Project Construction Standards; CREEI: Beijing, China, 2010.

28. National Energy Commission (NEA). Average Utilization Hours of Wind Power. 2012. Available online: http://www.nea.gov.cn/2013-04/08/c_132291257.htm (accessed on 16 December 2013).

29. Salvadores, M.S.; Keppler, J.H. Projected Costs of Generating Electricity; International Energy Agency: Paris, France, 2010.

30. National Development and Reform Commission (NDRC). Notice on Adjusting the Price of Coal Power; NDRC: Beijing, China, 2013.

31. Kang, J.; Yuan, J.; Hu, Z.; Xu, Y. Review on wind power development and relevant policies in China during the 11th Five-Year-Plan period. Renew. Sustain. Energy Rev. 2012, 16, 1907-1915.

32. State Council. The Development Plan for Strategic Emerging Industries during the 12th Five-Year-Plan Period. 2012. Available online: http:/www.gov.cn/xxgk/pub/govpublic/mrlm/ 201207/t20120720_65368.html (accessed on 16 December 2013).

33. National Energy Commission (NEA). The Development Plan for Wind Power during the 12th Five-Year-Plan Period; NEA: Beijing, China, 2012.

34. Ministry of Finance (MOF). Notice on Adjusting the Import Duty for Wind Turbine and the Key Components; MOF: Beijing, China, 2008.

35. State Administration of taxation (SAT). Notice on the VAT Policy for Comprehensive Utilization of Resources and Other Products; SAT: Beijing, China, 2008.

36. Morthorst, P.E. Policy Instruments for Regulating the Development of Wind Power in a Liberated Electricity Market; Riso National Laboratory: Roskilde, Denmark, 1999; pp. 7-12. 
37. Ministry of Finance (MOF). The Measures on the Collection and Usage of Renewable Energy Development Fund (Trial). 2012. Available online: http://www.mof.gov.cn/preview/hn/ lanmudaohang/zhengcefagui/201201/t20120112_623123.html (accessed on 16 December 2013).

38. Ministry of Finance of China, National Development and Reform Commission (MOF and NDRC). Notice on the Increase of Renewable Energy Surcharge Standard. 2013. Available online: http://www.mof.gov.cn/mofhome/mof/zhengwuxinxi/caizhengwengao/wg2013/ wg201309/201403/t20140319_1056897.html (accessed on 16 December 2013).

39. Peña, I.; Azevedo, I.L. Luís António Fialho Marcelino Ferreira. Economic analysis of the profitability of existing wind parks in Portugal. Energy Econ. 2014, 45, 353-363.

40. Joskow, P.L. Comparing the costs of intermittent and dispatchable electricity generating technologies. Am. Econ. Rev. 2011, 101, 238-241.

41. Ueckerdt, F.; Hirth, L.; Luderer, G.; Edenhofer, O. System LCOE: What are the costs of variable renewables. Energy 2013, 63, 61-75.

42. Sims, R.; Mercado, P.; Krewitt, W.; Bhuyan, G.; Flynn, D.; Holttinen, H. Integration of renewable energy into present and future energy systems. In IPCC Special Report on Renewable Energy Sources and Climate Change Mitigation; Edenhofer, O., Pichs-Madruga, R., Sokona, Y., Seyboth, K., Matschoss, P., Kadner, S., Eds.; Cambridge University Press: Cambridge, UK, 2011.

43. The State Council of China. The Strategic Action Plan of Energy Development 2014-2020; The State Council of China: Beijing, China, 2014.

44. Fertig, E.; Katzenstein, W.; Apt, J.; Jaramillo, P. The effect of long-distance interconnection on wind power variability. Environ. Res. Lett. 2012, 7, 034017.

45. Katzenstein, W.; Fertig, W.E.; Apt, J. The variability of interconnected wind plants. Energy Policy 2010, 38, 4400-4410.

46. Katzenstein, W.; Apt, J. The cost of wind power variability. Energy Policy 2012, 51, 233-243.

47. Lueken, C.; Cohen, E.; Apt, J. the costs of solar and wind power variability for reducing $\mathrm{CO}_{2}$ emissions. Environ. Sci. Technol. 2012, 46, 9761-9767.

(C) 2015 by the authors; licensee MDPI, Basel, Switzerland. This article is an open access article distributed under the terms and conditions of the Creative Commons Attribution license (http://creativecommons.org/licenses/by/4.0/). 